\title{
Patterns to explore cognitive preferences and potential collective intelligence empathy for processing knowledge in virtual settings
}

\author{
Salim Chujfi ${ }^{*}$ and Christoph Meinel
}

\begin{abstract}
Organizations continue building virtual working teams (Teleworkers) to become more dynamic as part of their strategic innovation, with great benefits to individuals, business and society. However, during such transformations it is important to note that effective knowledge communication is particularly difficult in distributed environments as well as in non-interactive settings, because the interlocutors cannot use gestures or mimicry and have to adapt their expressions without receiving any feedback, which may affect the creation of tacit knowledge. Collective Intelligence appears to be an encouraging alternative for creating knowledge. However, in this scenario it faces an important goal to be achieved, as the degree of ability of two or more individuals increases with the need to overcome barriers through the aggregation of separately processed information, whereby all actors follow similar conditions to participate in the collective. Geographically distributed organizations have the great challenge of managing people's knowledge, not only to keep operations running, but also to promote innovation within the organization in the creation of new knowledge. The management of knowledge from Collective Intelligence represents a big difference from traditional methods of information allocation, since managing Collective Intelligence poses new requirements. For instance, semantic analysis has to merge information, coming both from the content itself and the social/individual context, and in addition, the social dynamics that emerge online have to be taken into account. This study analyses how knowledge-based organizations working with decentralized staff may need to consider the cognitive styles and social behaviors of individuals participating in their programs to effectively manage knowledge in virtual settings. It also proposes assessment taxonomies to analyze online comportments at the levels of the individual and community, in order to successfully identify characteristics to help evaluate higher effectiveness of communication. We aim at modeling measurement patterns to identify effective ways of interaction of individuals, taking into consideration their cognitive and social behaviors.
\end{abstract}

Keywords: Computer Science; Telework; Knowledge management; Thinking styles; Learning styles; Self-government; Collective intelligence; Collaborative work; Cognitive patterns

\section{Introduction}

The combination of technology and necessity has helped to create a new way of organizing work - the virtual organization [1, 2]. Geographically distributed organizations are currently facing challenges when it comes to managing individuals that do not permanently work in typical office settings. Organizational communication patterns and corporate culture are different, since most of their interaction takes place through digital media and no longer face-to-face. This leads to many individuals feeling

\footnotetext{
* Correspondence: salim.chujfi@hpi.de

Hasso Plattner Institut, Prof.-Dr.-Helmert-Str. 2-3, 14482 Potsdam, Germany
}

increasing isolation from the organization, ambiguity in the tasks to be performed and less structure in the working environment.

Remote workers are brought together for a unified purpose or project and all usually answer to the same boss. However, they may be grouped into virtual teams according to their abilities. Leading those workers is a challenging task, with respect to collecting, categorizing and distributing their knowledge in order to make the organization perform better and to facilitate competitiveness.

Remote work has also gained in popularity, with many benefits resulting from the capacity to organize remote 
resources and create flexible working arrangements [3]. However, several researches have identified challenges that virtual settings engender [4]. For instance, the influence of trust and the difficulty of building it in virtual settings have received particular attention [5]. In response, researchers have proposed different approaches. Some of them look at the operational network structure of virtual organizations [4]; some investigate the interactions and communication among people within virtual organizations [6]. However, almost all studies consider only the organization and its teams in their analyses [7], with very little focus being placed on the variables at the individual level. Teleworkers' abilities, competences and behaviors, in fact, play an important role in generating the overall performance of distributed organizations. Collaboration should be personalized and not standardized.

\section{Background and literature review}

The most challenging aspects that staff today face when working in virtual settings are presented in Table 1. Irrespective of the technology used and how it is used, it is possible to identify that most aspects are related to individual competences and cognitive conditions which are not always properly identified and measured or even considered; in particular, when knowing that face-to-face communication does not take place as happens in normal office settings.

The significance of managing knowledge within firms so as to be competitive, combined with the distributed or discontinuous essence of virtual organizational forms, places enormous challenges on today's business leaders who are driven to seek optimal firm performance [8]. A

Table 1 Challenges facing staff when working remotely [65]

\begin{tabular}{|c|c|}
\hline Challenges & Description \\
\hline Lack of self- discipline & $\begin{array}{l}\text { Staff not confident to perform assigned } \\
\text { work effectively }\end{array}$ \\
\hline Lack of self-management & Staff not able to manage themselves \\
\hline $\begin{array}{l}\text { Lack of organizational } \\
\text { engagement }\end{array}$ & Staff do not feel a part of the organization \\
\hline Lack of Coordination & $\begin{array}{l}\text { Staff lack direction and instructions from } \\
\text { management }\end{array}$ \\
\hline Lack of Motivation & Staff lack empowerment and feedback \\
\hline Lack of Feedback & $\begin{array}{l}\text { Staff lack information to continue } \\
\text { performing activities }\end{array}$ \\
\hline Social isolation & Staff lack contact with others \\
\hline Distractions & Staff not able to focus on assigned work \\
\hline Slow communication & Staff not able to effectively communicate \\
\hline Work-Life balance & $\begin{array}{l}\text { Staff not able to separate private and } \\
\text { work life }\end{array}$ \\
\hline Ambiguity & $\begin{array}{l}\text { Staff confused about how to proceed } \\
\text { due to vagueness }\end{array}$ \\
\hline Less Structure & Staff lack organizational structure \\
\hline
\end{tabular}

major advantage of virtual organizations is that they help exploit the knowledge of distributed employees with diverse backgrounds and experience [9, 10]. However, the underpinning element of virtual organizations, computer-mediated communication (CMC), has been criticized for its limited capacity to transmit rich information and its consequent ineffectiveness in transferring non-codified knowledge [11].

One of the most widely recognized problems in knowledge management is that tacit knowledge is difficult to transfer $[1,4]$. From a communication perspective, this can be explained by the stance that lean (non face-toface) communication channels in virtual settings do not provide adequate support for the necessary transfer of rich information in order to assist the recipient to acquire tacit knowledge [12]. This may be a technologybased issue, but it also implies a communication skill problem that needs to be addressed individually. Either way, knowledge transfer is likely to become more effective if there is a way to improve the effectiveness of communication in virtual settings [13]. Our attempt is to approach knowledge transfer in virtual settings from a social cognitive perspective at the level of the individual, modeling a set of patterns with consideration of cognitive styles and learning styles, in order to achieve higher effectiveness of communication in virtual settings. We propose a model to appraise cognitive preferences, skills and abilities that enable individuals to undertake effective knowledge transfer in distributed environments and assist in designing hypermedia technologies (Personal Knowledge Support Interfaces) to overcome the limitations of such settings. Figure 1 presents the relevant aspects we consider for combining the two elements to build up the pattern in a structured way.

1. Self-government to work remotely and participate in virtual teamwork.

2. Cognitive preference to process knowledge. Hypermedia preferences.

\section{Cognitive styles}

Our analysis of the nature of knowledge is based on Polany's theory, arguing that knowledge requires active participation of the knower and is hence knowerdependent. Knowing is an act of a particular individual, closely related to his or her cognitive preferences. Each time we express ourselves to say what we know, we can only do so by sending messages in different forms. Such messages, however, for the most part, carry information which only a knowing mind can assimilate, understand and incorporate into its own knowledge structures [14]. Irrespective of how we codify and store knowledge, it does not seem to have much meaning until it is used for some purpose. The fundamental perception is to 
Individual Cognitive perspectives in Virtual Settings

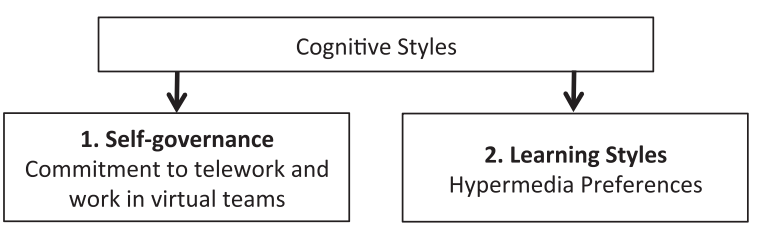

Fig. 1 Relevant aspects for social cognitive analysis of individuals working in virtual settings

understand how the knower's cognitive style can influence knowledge sharing through collaborative virtual environments. De Bono [15] believed that cognitive style is required to facilitate a knowledge management system in terms of helping the individual to identify appropriate information and to be able to transfer it at the accurate location. Harrison and Bramson [16] and De Bono [15] found that understanding thinking is vital in resolving problems and that it is essential to know how people think to avoid misunderstanding.

Previous researchers in this area attempted to explain the relationship of knowledge transfer and cognitive styles through issues such as personality traits and behavioral impact on knowledge sharing. Kwok and Gao [17] identified that there are some studies that have been done related to knowledge sharing through virtual environments in organizations. In addition to that, Soule [18] and Zakaria et al. [19] also added some contributions to the findings of virtual knowledge sharing among team workers. However, no empirical study has as yet been done to integrate individual cognitive styles such as we propose in this study.

Ghani et al. [20] performed an empirical analysis and showed strong support for the positive effects of the five categories of thinking styles described in Sternberg's theory [21], namely Functions, Levels, Forms, Scopes, and Leanings. The five categories show that there are several ways of managing a society, as well as different ways for people to demonstrate their abilities and skills. The preferences that they indicate for choosing one's abilities are classified as the styles of thinking. According to Sternberg [21], Functions include legislative, meaning being creative, executive, meaning being conforming, and judicial, meaning analytical. Forms are related to the hierarchical description of people who deal with multiple prioritized tasks, Levels consist of a global thinking style, used for people who focus on abstract opinions, and local, used for people who concentrate on concrete ideas. Scopes cover internal thinking style, used for people who prefer to work independently, and external thinking style, used for people who prefer to work with others. In addition, Leanings include a liberal thinking style to describe people who use new ways of dealing with tasks, and a conservative thinking style to describe people who use traditional ways of dealing with tasks. Sternberg added that the style of thinking is correspondingly related to the other styles, such as a cognitive approach as well as a leaning style and many other styles that are constructed from intellectual styles.

We have long accepted that people are not all the same, why then should they be treated in the same way when considering that their cognitive preferences can significantly improve the way they think, make decisions and interact? People organize and govern their tasks in ways that are consistent with how they cognitively formulate concepts and process information [22]. These are known in Cognitive Psychology as Cognitive Styles or Thinking Styles. When the cognitive styles and environment are compatible, individuals are better equipped to attend to and interpret relevant information and use it to decide how to act and perform effectively [23]. Cognitive styles also affect preferences for the ways of governing interaction among groups [22, 24].

Considering Styles, it is important to mention that they are preferences and not abilities. Styles are not good or bad, and can vary across the lifespan. What is valued at one time and place may not be valued at another.

There are several models developed to evaluate cognitive styles. Whether the model is the one designed by Myers-Briggs, by Sternberg, by Dunn and Dunn, by Gregorc, by Gardner, or by Kolb, the basic message is the same: nothing is more unequal than treating individuals as though they were equals in all ways [25]. This study formulates a hybrid model, combining some aspects of Sternberg's theory of mental self-governance and others from the Felder and Silverman learning styles, defining the structured setting as a two-step process involving the abilities of individuals to work remotely and to work in virtual settings and also their preferences to collect and process information.

According to Sternberg's theory, people can be understood in terms of the functions, forms, levels, scopes, and leanings of governance. Three dimensions of this taxonomy were identified as relevant to the nature of remote work and virtual teams: scope, leaning and level [26]. Table 2 presents the categories of each dimension and how this study approaches their relevant aspects.

Sternberg's theory of mental self-government reflects different ways in which people can organize or govern themselves. From this viewpoint, then, governments are very much extensions of individuals: They represent alternative ways in which collectives, like individuals, can organize themselves [22]. Evaluation of the commitment of individuals to work remotely and also to take part in virtual teamwork is considered in particular. 
The following three premises are considered for classifying the dimensions according to their strengths and weaknesses.

Levels:

Because local cognitive styles prefer concrete detail in their work, whereas global cognitive styles prefer abstract thinking, and remote work elevates ambiguity, people with global cognitive styles will have greater commitment to working remotely than people with local cognitive styles [26]. In addition to that, because the nature of virtual collaboration involves heightened ambiguity from a traditional office setting, these differences are surmised to disproportionately increase the cognitive costs of information exchange for locals during virtual collaboration [27, 28]. Thus, people with global cognitive styles will have greater commitment to the virtual team than people with local cognitive styles [26].

Scopes:

Because internal cognitive styles prefer to work alone rather than in a group, it would follow that employees with internal cognitive styles would be well-suited to remote work and this match between their cognitive style and the situation would probably be associated with high levels of commitment [26]. This means that people with internal cognitive styles will have greater commitment to working remotely than people with external cognitive styles. On the other hand, remote workers seeking out interaction with their virtual team members [..] have been shown to increase identification with and commitment to coworkers [29]. Thus, people with external cognitive styles will have greater commitment to

Table 2 Cognitive style dimensions relevant to the nature of working remotely and in virtual teams

\begin{tabular}{ll}
\hline Thinking Styles & \\
\hline Global & $\begin{array}{l}\text { Individual likes to deal with big ideas, but sometimes } \\
\text { can lose touch with the details (able to process } \\
\text { abstract information) } \\
\text { Individual enjoys tasks that require keeping track of } \\
\text { details and focusing on concrete specifics of a situation } \\
\text { (requires concrete details) }\end{array}$ \\
Local & $\begin{array}{l}\text { Individual is typically introverted and often } \\
\text { Internal }\end{array}$ \\
External & $\begin{array}{l}\text { Individual might not enjoy working or even being } \\
\text { alone (prefers working on teams) }\end{array}$ \\
3. Leanings & $\begin{array}{l}\text { Individual may prefer change simply for the sake } \\
\text { of change, even when it is not ideal (goes beyond } \\
\text { biberal }\end{array}$ \\
boundaries) \\
Individual likes to minimize change and avoid ambiguity \\
(prefers conventions and structures)
\end{tabular}

the virtual team than people with internal cognitive styles [26].

Leanings:

Since the remote work function has limited capability to support observational modeling [11,30], and because it has increased discretion and reduced feedback compared to traditional office settings [31-33], the remote work function is less externally structured. Since congruence between a person's cognitive style and the person's task environment is an important condition for building commitment [30, 34], liberals should be more committed to the less structured environment of remote work than conservatives [26].

Table 3 is developed using ' - ' and ' + ' to indicate the low and high affinity of the respective dimension to remote work and virtual teamwork.

\section{Remote work vs virtual team work}

Civin [35], Fusaro [36], Jehng [30], Wellman [37] have suggested that the ambiguous, solitary and less externally structured nature of an environment in which electronic media are used for collaboration adversely affects teleworkers' commitments toward their jobs and their virtual teammates. It should be noted that low remote working commitment is not ubiquitous among teleworkers [38]. Cerulo [39] and Ngwenyama [40] have asserted that an electronically mediated environment may enhance one's feelings of freedom and flexibility in one's work, and that people at times may develop spontaneous intimacy and solidarity with virtual coworkers $[39,40]$. Some ways in which the effects are seen concern one's proclivity for working alone or as part of a group.

While there are many factors that affect preferences for working alone versus working in a team, such as cultural individualism and collectivism [41], the differential perceptions of remote work and virtual teammates depend in part on the compatibility between people's cognitive styles and the richness of the media through which they collaborate with their virtual teammates while performing their duties [23, 42, 43]. In accordance with this, we consider evaluating learning style models and media richness to identify individual's learning preferences, in order to determine the ideal tools and environment in which knowledge can be processed better.

\section{Learning style models}

In addition to the geographic location of the individual and his/her commitment to work remotely and in virtual teams, this study integrates learning style models to enhance Sternberg's theory of mental governance, to identify the individual's learning preferences in order to determine the ideal environment (and media) in which knowledge can be processed better. It also allows organizations to effectively address content and communicate with individuals. 
Table 3 Affinity of cognitive styles related to remote work and virtual teamwork

\begin{tabular}{lll}
\hline Styles & Remote Work & Virtual Team Work \\
\hline Levels & & - \\
Global & + & + \\
Local & - & \\
Scopes & & - \\
Internal & + & + \\
External & - & \\
Leaning & & - \\
Liberal & + & + \\
Conservative & - & \\
\hline
\end{tabular}

There are two known models of learning styles that are considered in this study, as they show good discriminant validity with a strong relationship between the dimensions being statistically significant: the Gregorc's Mind Styles Model which provides an organized method of considering how the mind functions, and the Felder and Silverman's Learning Style Model (FSLSM). Gregorc's model focuses on perceptions and abilities to evaluate how individuals perceive information from the world and how it is organized. However, Felder and Silverman developed their model considering an index to identify preferences out of four dimensions, allowing individuals to develop a more balanced approach to learning. This study considers FSLSM, since it better assists in associating the individual's virtual setting conditions with the preferences of the individual out of the range of predilections, to balance the knowledge experience.

The Felder model is most appropriate for hypermedia courseware [24], which is also a common setting for individuals working remotely and very often used in research related to learning styles in advanced learning technologies.

Table 4 presents how FSLSM classifies individuals as fitting into the following four learning style dimensions:

When we evaluated levels and scopes according to Sternberg's theory, we considered individuals' preferences for working alone or within teams (active/reflective learners) and also reviewed abstract and concrete thinking (sensing/intuitive learners). Therefore, we now consider analyzing only visual/verbal learners and sequential/global learners out of the four dimensions suggested by FSLSM, specifically considering the impact on using hypermedia tools in virtual settings.

The visual-verbal dimension differentiates learners who remember best what they have seen, e.g. pictures, diagrams, time lines, films, demonstrations and flow-charts, from learners who get more out of written words and spoken explanations. Thus, visual individuals should effectively process explicit knowledge delivered in video format or digital material that has a visual representation. In contrast, verbal individuals will be expected to process and transmit knowledge more effectively in virtual settings using tools such as messaging, blogs, forums or e-mail systems. Interaction by the use of video teleconferencing or audio systems should also be suited to their verbal learning style.

In the sequential/global dimension, individuals are characterized according to their understanding. Sequential learners tend to gain understanding in linear steps, while global learners tend to learn in large jumps, absorbing material almost randomly without seeing connections. Sequential learners tend to follow logical stepwise paths in finding solutions; global learners may be able to solve complex problems quickly or put things together in novel ways once they have grasped the big picture. [15]. Because the whole picture is important for global learners, they tend to be more interested in overviews and a broad knowledge, whereas sequential learners are more interested in details.

Table 5 uses '-' and '+' to indicate the low and high affinity of seven common computer-mediated hypermedia tools used in virtual settings to the learning topics considered relevant to obtaining and sharing knowledge.

\section{Research design and methodology \\ Collective Intelligence}

There is a form of intelligence that emerges from the collaboration and competition among many individuals and that has a mind of its own. This collaboration in human collectives can either be direct or indirect, and the interaction can take place through verbal communication or non-verbal action. No geographic or spatial dimension is as yet known as a precondition for its effective development either.

The acquisition and sharing of knowledge in Collective Intelligence is a big contest compared to traditional

Table 4 Learner types' style dimensions relevant to the nature of working remotely and in virtual teams [66]

\begin{tabular}{ll}
\hline Learner types & Description \\
\hline Active & Prefers to learn by trying things out, \\
& working with others \\
Reflective & Prefers to learn by thinking things \\
& through, working alone \\
Sensing & Prefers the concrete, practical, oriented \\
Intuitive & towards facts and procedures \\
Visual & Prefers the conceptual, innovative, oriented \\
Verbal & towards theories and meanings \\
Sequential & Prefers visual representations of presented \\
& material: pictures, diagrams, flow charts \\
Global & Prefers written and spoken explanations \\
& Prefers the linear, orderly, learning in small \\
& incremental steps \\
& Prefers the holistic, systematic thinking, \\
& learning in large leaps
\end{tabular}


methods of information sharing. Managing Collective Intelligence poses new challenges, such as semantic analysis within a particular context, arising both from the content itself and the social context. In addition, the social dynamics given by remote environments have to be taken into account, not only at the level of the community, but at the level of individuals as well.

Considering all the requirements previously mentioned, this study presents the decomposition of Collective Intelligence into four layers as a methodological approach for research and development. It separates different concerns into orthogonal layers specifically representing the individual's cognitive preferences and behaviors in remote environments (communities). Figure 2 represents the concept of how the four layers are considered for the support of the effective transformation of information into knowledge. The levels are not exclusive and the arrows consider the sharing activities that allow information to be processed, taking into consideration affinities in the environment with other peers.

Figure 3 represents how the exchange of information concerns different teleworker layers. The behaviors are identified and analyzed at individual level and are used to evaluate and synchronize preferences and abilities for supporting an effective information sharing.

Collective Intelligence also refers to the intelligence and knowledge that arise from interactions among individuals who are associated in groups. To analyze those groups (or teams), it is necessary to go beyond their unique qualities and also to consider characteristics such as interaction, interdependence, structure, cohesiveness and goals.

Groups are systems that create, organize, and sustain interaction among the members. Figure 4 recognizes that members' thoughts, actions, and emotions are shaped by individual-level processes, but that each member is also shaped by the group to which he belongs. These groups are at the same time shaped by their individual members and they are also nested in larger groups themselves, including communities and organizations.

Allport [1] initially believed that group behavior was completely predictable, by considering the characteristics and qualities of the individual members. But Kurt Lewin's [44] field theory of group dynamics assumed that groups are more than the sum of their parts.
Lewin's theory is based on the principle of interactionism, assuming that the behavior of people in groups is determined by the interaction of the person and the environment. The following formula summarizes this assumption.

$$
\mathrm{cB}=f(\mathrm{I}, \mathrm{E})
$$

cB: Cognitive Behavior, I: Interaction, E: Environment

The process of collecting and managing knowledge in remote environments is performed with the use of digital tools that allow the exchange of information. The richer the medium, the better it facilitates collaboration and enhances attendant clarity and understanding among collaborative partners $[11,30]$. The richness serves to reduce the feeling of solitude and the ambiguity created by electronic mediation surrounding tasks and interpersonal situations. This affects how people feel about their tasks and come to identify with one another and ultimately impacts their commitment to their work and their virtual teammates $[45,46]$.

In order to analyze behaviors more precisely, Formula 2 shows how interaction is defined within the function of cognitive styles and how learning preference is defined within the function of the environment, meaning the media assisting the activities associated with knowledge collection and transference. Defining the learning preferences within the function of the environment will lead the evaluation to a more accurate representation of a teleworker's knowledge-processing capabilities and therefore enhance the potentials of adaptive learning environments, specifically considering the digital media used to interact and share knowledge. Moreover, the in-depth investigation of learning style characteristics could also improve pedagogical models, supporting a more effective and personalized learning.

Our approach in virtual settings considers how the interaction of individuals may be affected by their thinking styles (Ts) and how the environment is impacted by the digital media used in computer-mediated communication - CMC - which is specifically analyzed in this study through learning preferences (Lp).

$$
\mathrm{cB}=f(\mathrm{I}(\mathrm{Ts}), \mathrm{E}(\mathrm{Lp}))
$$

Ts: Thinking styles, Lp: Learning preferences

\begin{tabular}{|c|c|c|c|c|c|c|c|}
\hline Learning & E-mail & Instant Messaging & Blog Forums Wikis & Social Networks & Video Streaming & Voice Podcasts & Video-conferencing \\
\hline \multicolumn{8}{|l|}{ Media } \\
\hline Visual & - & - & - & + & + & - & + \\
\hline Verbal & + & + & + & + & + & + & + \\
\hline \multicolumn{8}{|l|}{ Order } \\
\hline Sequential & + & + & + & + & + & + & + \\
\hline Global & - & - & + & - & + & - & + \\
\hline
\end{tabular}

Table 5 Affinity of hypermedia tools relevant to obtaining and sharing knowledge in virtual settings 


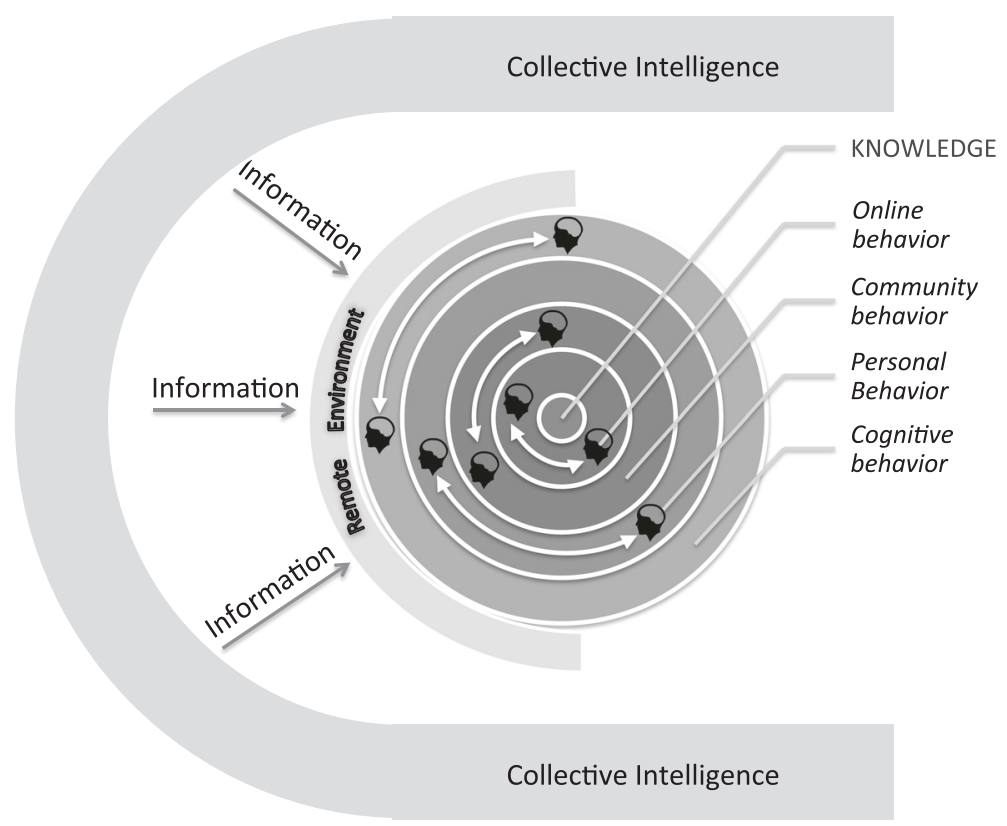

Fig. 2 Exchange of information considering different teleworker layers

There has been a large volume of work on content analysis. Researchers have investigated various methods to rate sentiment levels, to detect moods and emotions, and finally, to understand the source, target, and complex attitude types [29]. Others have attempted to analyze Impacts, aiming to understand the potential effects of group interaction processes on each other and on participants. A few recent approaches have utilized more complex methods, such as clustering, to directly assess the potential impact of one variable on another [47].

Recognizing behavior and interaction patterns, we attempt to catalog potential Collective Intelligence empathy based on cognitive preferences, considering the McGrath [48] interaction processes at a micro level. Figure 5 shows interaction in terms of three different stages: communication pattern among interacting people, content of communications, as well as impact of different group interaction processes on each other and on participants.

Communication pattern refers to the structure of a series of interactive behaviors that takes place among people [48]. Such behaviors can also be considered with respect to their content and can be regarded as having an interpersonal component (Thinking Styles) and a task component (Media). Finally, the interaction process concerns its impact, mainly built up by the interaction of communications, content and tasks.

A/B: Group Members

Form: A/C, C/B: Online Communication process Content: T/A, T/B: Interpersonal activity (Thinking)

M/A, M/B: Media activity (Learning)

Outcome:
$\mathrm{T} / \mathrm{C}, \mathrm{C} / \mathrm{T}$ : Effect of Communication pattern and interpersonal component.

C/M, M/C: Effect of Communication pattern and task component.

I/M, M/I: Effect of interpersonal and task component on one another.

After identifying actors and influences, with respect to the McGrath [48] interaction processes, we proceeded to analyze the individual's behaviors, targeting the threestage process of the virtual settings' environment, namely: Personal, Community and Online.

The consensus is that individuals in a community who possess more of a certain type of competence will perform better at related tasks than other less competent individuals [49]. Consistent with this finding, we extend and conceptualize the analysis of individuals' behaviors within virtual settings and communities, so that they maximize their performance in processing knowledge. We base our theorizing on:

Personal Behavior through the Social Cognitive Theory Community Behavior through the Social Capital Theory Online Behavior through the Social Presence Theory

In the context of virtual settings, individual competence can be defined as the extent of an individual to work and communicate in remote environments for driving the achievement of collaborative work. We believe that individuals are inexperienced and ineffective at communicating in virtual environments, particularly when the goal is knowledge transfer leading to the development or 


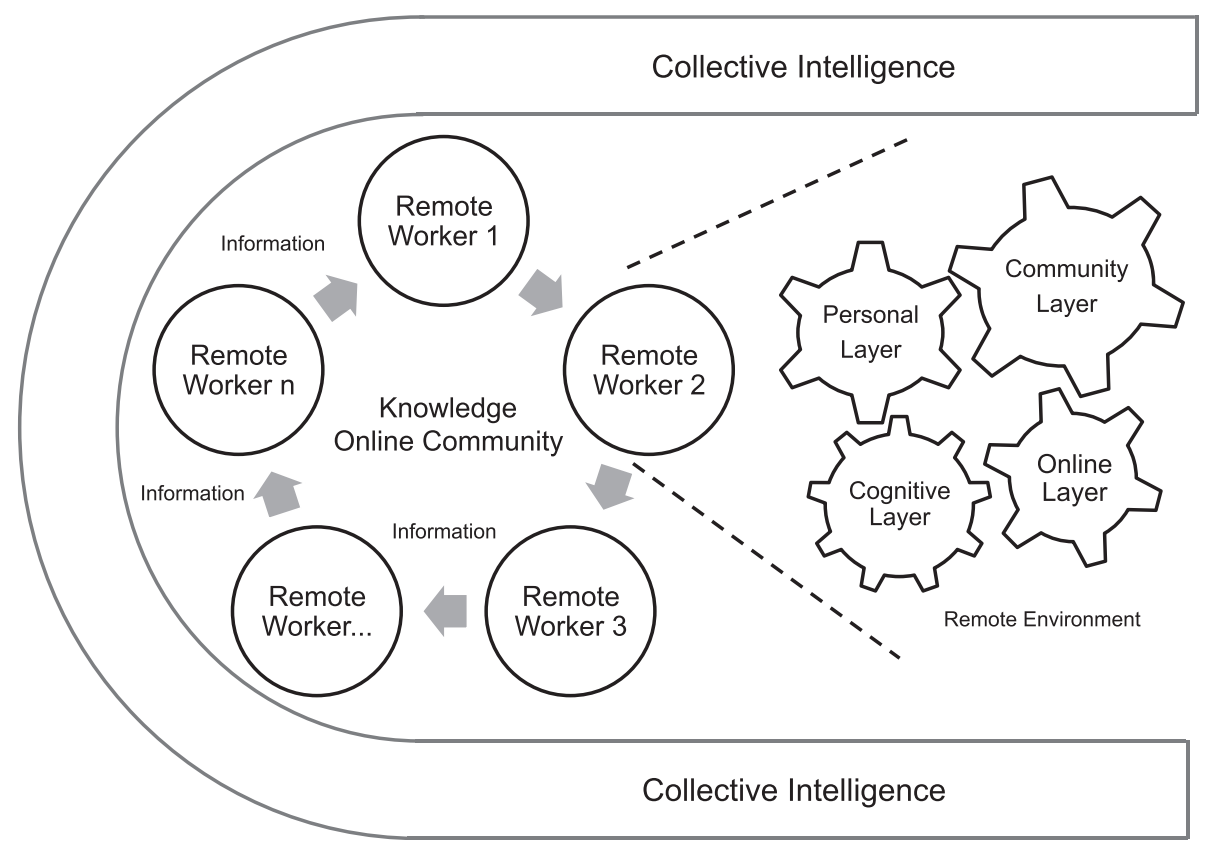

Fig. 3 Decomposition of Collective Intelligence into four layers as a methodological approach

acquisition of new skills by the recipient, because it is such a new phenomenon [50]. The analysis of individual behaviors that may affect interaction is approached with the respective theories as follows:

The Social Cognitive Theory (SCT) considers a psychological model of behavior that was defined by Albert Bandura [51]. It emphasizes that learning occurs in a social context and that much of what is learned is gained through observation. SCT does recognize the importance of the environment in determining behavior, but in addition it claims that people, through forethought, selfreflection, and self-regulatory processes, can also exert substantial influence over their own outcomes and the environment more broadly. SCT also assumes that learning involves not just the acquisition of new behaviors, but also of knowledge, cognitive skills, concepts, abstract rules, values, and other cognitive constructs. This division of learning and behavior is a shift from the position advocated by behavioral theories that defined learning stridently as a change in the form or frequency of behavior.

SCT is used in this study as a method to measure selfefficacy and the belief in own ability with minimal supervision, relying on own abilities and initiative to perform a job, taking into consideration the conditions of a remote environment.

For Field [52], the central thesis of the Social Capital Theory is that 'relationships matter'. The central idea is that 'social networks are a valuable asset'. Interaction enables people to build communities, to commit themselves to each other, and to weave the "social knowledge fabric". A sense of belonging and the concrete experience of social networks (and the relationships of trust and tolerance that can be involved) can provide great benefits to people. Social capital is "the aggregate of the actual or potential resources which are linked to possession of a durable network of more or less institutionalized relationships of mutual acquaintance and recognition" [53].

This study uses the Social Capital Theory as a way of identifying and measuring the constituents that compose virtual networks and how they influence individuals' behaviors.

The Social Presence Theory (SPT) has come to be viewed as the way individuals represent themselves in their online environment. Social presence defines how participants relate to one another, which in turn affects their ability to communicate effectively [54]. Studies have found that academic performance can actually be inhibited due to a lack of social presence in online classrooms. Without social presence, learning interaction suffers, which has negative effects on learning performance [55].

Interactivity involves the activities and communication styles online users engage in. Norton [56] identified 11 communication styles that can be associated with online communication. What style participants use in communicating will impact on their social presence. Too much rigidity to one style alone, or poor use of all styles in the facilitation of conversations, will have a negative effect on social presence. 


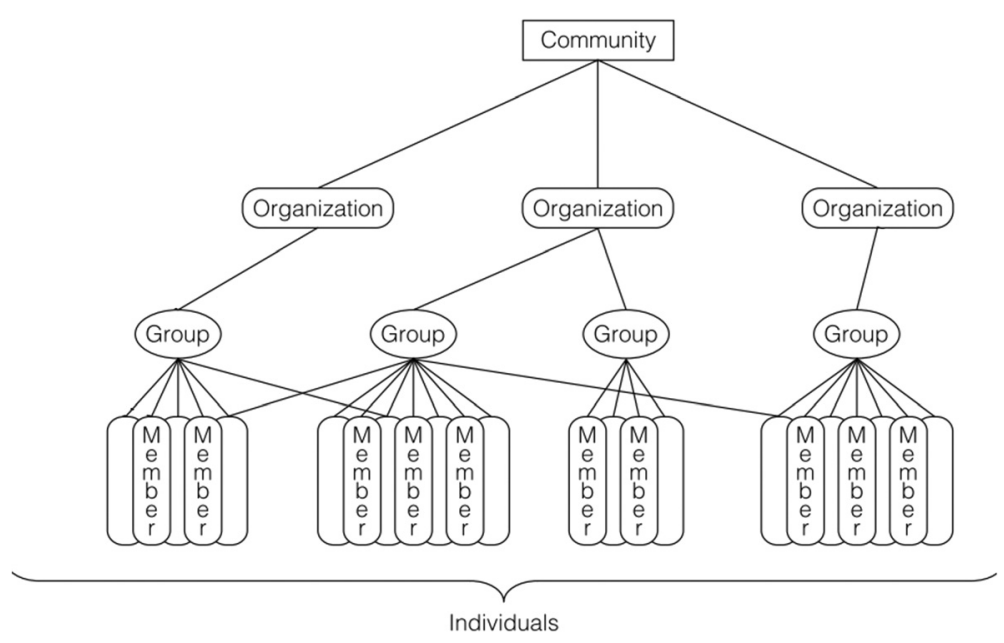

Fig. 4 Multilevel system of nested relation of individuals in larger social units [11]

The Social Presence Theory is considered in this study as a way of measuring the feeling of community that someone experiences in an online environment, so that cohesiveness and collaboration in virtual operations can be promoted.

Bandura [51] suggested as well that individuals develop cognitive and other personal traits through behaviors. In the same vein, virtual competences are influenced when individuals conduct virtual activities. Since individuals are exposed to virtual activities in both work life and daily life, they are likely to develop virtual competences in both settings [57]. The effect of this constitutes the influence process that, according to a study by Woodley [58], has shown it is correlated with the development of Collective Intelligence. Therefore, we hypothesize that:

H1: The relationship between cognitive and social behaviors of individuals is positively related to the development of Collective Intelligence empathy in virtual settings.

\section{Results and discussion}

\section{Instrumentation}

A modeling approach for defining cognitive patterns of individuals working in virtual settings is proposed, aimed at identifying their tendencies in each of the three of Sternberg's dimensions and the two dimensions of FSLSM. Firstly, Self-Government topics are evaluated using the Thinking Style Inventory (TSI) to deal with determining the relevant scores of individuals working in virtual teams and working remotely, by identifying cognitive styles. Subsequently, the Index of Learning Styles (ILSs) is used to measure the relevant preferences, to determine the ideal environment in which knowledge can be processed better and thus to determine hypermedia tool preferences.

\section{Mental self-government pattern}

Sternberg's Thinking Style Inventory (TSI) is incorporated in this study to collect information about three

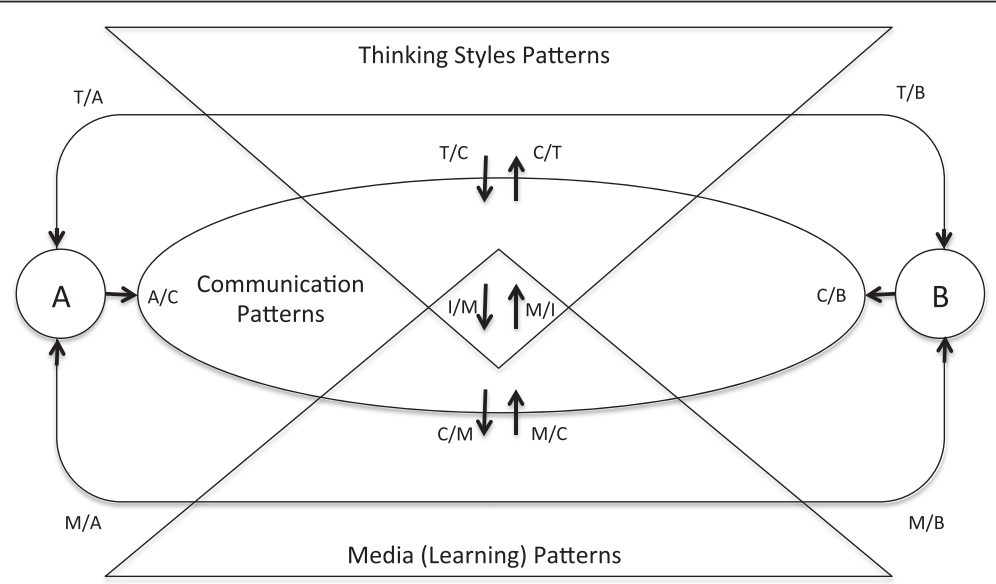

Fig. 5 Adapted interaction three-stage process of McGrath [48] 
dimensions: scope, level and leaning, and their respective styles. Each dimension consisted of 8 questions, in total 48. Responses to dimensions are coded from 1 to 7 , where higher scores indicate greater affinity and lower scores represent a lower affinity as follows:

(1) Not at all well, (2) Not very well, (3) Slightly well, (4) Somewhat well, (5) Well, (6) Very well, (7) Extremely well.

By adding up all the hints and dividing them by the number of answers providing valid information, a measure for each of the six styles can be individually calculated, using the mathematical notation shown in Formula 3, where $\mathrm{x}$ denotes a hint value for each $\mathrm{i}$ question providing valid information. The $\mathrm{x}$ can have a value in the range of 1 to 7 , and $\mathrm{n}$ denotes the number of questions providing available information.

$$
\frac{\sum_{i=1}^{n} x_{i}}{n} \text { where } 1 \leq x \leq 7
$$

According to the affinities described in Table 2, the high or low values obtained of each style indicate a specific remote work preference and empathy for virtual teamwork.

\section{Learning patterns}

The approach involving calculating hints for specific learning style preferences is based on the Index of Learning Styles (ILS) proposed by Felder \& Soloman [59]. To collect the dimensions of learning style: media and order, individuals are asked to answer 11 questions for each learning style, in total 22. For calculation of learning styles from patterns of behavior, only questions related to Visual/Verbal and Sequential/Global dimensions are considered.

Each question has only two possible answers, "a" or " $\mathrm{b}$ " and the answer to each question increments linearly +1 the amount of a's or b's of the dimension. By adding up all a's and b's, the total value has to be equal to 11, as noted in the mathematical notation shown in formula 4 .

$$
\sum_{n=1}^{11}\left(a_{n}+b_{n}\right)=11
$$

To calculate the value for each of the two scales, it is necessary to subtract the smaller total from the larger one, this is done by writing the difference ( 1 to 11$)$ and the letter ( $\mathrm{a}$ or $\mathrm{b}$ ) for which the total was larger. Formula 5 and Formula 6 show the mathematical notation.

$$
\text { if } \begin{aligned}
\sum_{n=1}^{11}\left(a_{n}\right) & >\sum_{n=1}^{11}\left(b_{n}\right) \text { then score a } \\
& =\sum_{n=1}^{11}\left(a_{n}\right)-\sum_{n=1}^{11}\left(b_{n}\right)
\end{aligned}
$$

$$
\text { if } \begin{aligned}
\sum_{n=1}^{11}\left(a_{n}\right) & <\sum_{n=1}^{11}\left(b_{n}\right) \text { then score } b \\
& =\sum_{n=1}^{11}\left(b_{n}\right)-\sum_{n=1}^{11}\left(a_{n}\right)
\end{aligned}
$$

The scores obtained for each dimension ( $\mathrm{a}$ or $\mathrm{b}$ ) need to be placed at the appropriate location on the respective scales shown below.

Media:

$$
\begin{aligned}
& \text { Visual } \\
& \text { Verbal } \\
& \text { 11a...9a...7a...5a...3a...1a...1b...3b...5b...7b...9b...11b }
\end{aligned}
$$

Order:

Sequential

11a...9a...7a ..5a...3a...1a ...1b...3b...5b...7b...9b...11b

If the score on a scale is $1-3$, individuals are fairly well balanced on the two dimensions of that scale.

If the score on a scale is $5-7$, individuals have a moderate preference for one dimension of the scale and will process knowledge more easily in an environment that favors that dimension.

If the score on a scale is $9-11$, individuals have a very strong preference for one dimension of the scale. Individuals have real difficulty processing knowledge in an environment that does not support that preference.

According to the affinities described in Table 3, the high or low occurrence of these patterns indicates a tendency to learn and process knowledge with specific empathy and effectiveness for each hypermedia tool.

\section{Cognitive behavior layer}

Formula 7 is the extension of Formula 2, previously defined and based on Lewin's Theory, and helps to define more precisely the factors of cognitive Behavior $(\mathrm{cB})$, by means of adding the Virtual Teamwork (VTw) scores of each of the three dimensions: scope, level and leaning. The factor environment is also extended in the formula, considering mainly the scores of the Verbal and Sequential learning preferences, since they cover the widest spectrum of tools to support computer-mediated communication - CMC.

$$
\text { cognitive Behavior }=f(\mathrm{I}(\mathrm{Ts}), \mathrm{E}(\mathrm{Lp}))
$$

Where

$$
\begin{aligned}
& \mathrm{I}(\mathrm{Ts})=\text { Scope }(\mathrm{VTw})+\text { Level }(\mathrm{VTw})+\text { Leaning }(\mathrm{VTw}) \\
& \mathrm{E}(\mathrm{Lp})=\text { Media }(\text { Verbal })+\operatorname{Order}(\text { Sequential })
\end{aligned}
$$

\section{Personal behavior layer}

The Social Cognitive Theory is considered, using the General Self-Efficacy Scale (GSE) to measure selfefficacy. The basic idea is that motivation and performance are determined by how successful people believe 
they can be [4]. This is useful in the workplace, since it is possible to develop and improve self-efficacy beliefs in teams by focusing on four primary sources $[4,65]$.

The General Self-Efficacy is self-administered, as part of a comprehensive questionnaire. 10 items are mixed at random into a larger pool of items that have the same response format. Responses are given on a 4-point scale as shown in Formula 8. By adding up all responses to all 10 items, it is possible to calculate the final composite score with a range from 10 to 40 .

According to the affinities described in Table 6, the high or low scores obtained indicate a tendency of individuals to rely on their own abilities and initiative to perform their jobs independently in virtual environments with minimal supervision. Each item used in the evaluation refers to successful coping and implies an internal-stable attribution of success. Perceived self-efficacy is an operative construct, i.e. it is related to subsequent behavior and therefore can be regarded as a positive resistance resource factor.

$$
p B=\sum_{n=1}^{10} I n
$$

\section{Community behavior layer}

The Social Capital Theory is introduced to complement the Social Cognitive Theory and extend the analysis of the capabilities of individuals to interact within groups. The most comprehensive definitions of social capital are multidimensional, incorporating different levels and units of analysis.

Much emphasis has been put on social networks and their sizes, but much less on the resources that could be accessed through the network ties, and how these may become available to the individual [60]. In addition to that, measurements have mostly been designed for a specific life domain only, and not with the aim of investigating the 'general' social capital of a general population. To overcome these disadvantages, Snijders [61] proposed combining the positive aspects of a measurement instrument that has been used to collect access-type social capital, called the 'Position Generator' [62, 63]. Using more clear referral to specific resources, and omitting name identification from name generator questions, the resulting instrument, the 'Resource Generator', inquires about access to a fixed list of

Table 6 Characteristics of Self-Efficacy [66]

\begin{tabular}{ll}
\hline High Self-Efficacy & Low Self-Efficacy \\
\hline Self-confidence & Fear of risks \\
Accurate self-evaluation & Fear of uncertainty \\
Willingness to take risks & Feelings of failure \\
Sense of accomplishment & Impression management \\
\hline
\end{tabular}

resources covering several domains of life. This instrument can be administered rapidly, and can result in valid and easily interpretable representations of social capital.

This study considers the Resource Generator [57] as a survey instrument for the measurement of individual social capital, as it directly refers to accessed social resources instead of occupational prestige.

We considered using the questionnaire items which were used in the 1999/2000 nationwide study: "Social relations and networks in the neighborhood and at the workplace: the Social Survey of the Networks of the Dutch" (SSND). A set of 18 questions, that can be summarized in four dimensions, are designed to be applied as personality covariates to explain distributions of social capital measures as follows:

1. The desire for more social contacts or, conversely, satisfaction with the present network. (Sc)

2. Propensity to make/discover new contacts. (Nc)

3. Integration of different types of relationships in the network. (Ir)

4. Expectation and propensity to mobilize social resources. (Ms)

$$
c m B_{n}=\sum_{n=1}^{i} S c(n)+\sum_{n=1}^{j} N c(n)+\sum_{n=1}^{k} \operatorname{Ir}(n)+\sum_{n=1}^{m} M s(n)
$$

The idea behind this is to explore dimensions in the set of items, and transform each into a social capital scale. Since there is no real notion of volume in this evaluation, the measurement refers to how bigger, larger, or more social capital is beneficial for attaining community behavior, and therefore it is calculated linearly. It also provides some insights into the components that may influence individuals' conduct within virtual networks.

\section{Online behavior layer}

The Social Presence Theory is introduced with the Networked Minds Social Presence Inventory [64] as an evolving set of self-report scales. This study assesses various levels of social presence from simple co-presence to more intense feelings of psychological and behavioral accessibility and interaction.

The measures are designed for assessing interaction with others, considering mediatic interfaces, such as:

1. Users' interaction with others via wide screen or teleconferencing.

2. Users' experience in collaborative virtual environments.

3. Users' chats with artificial intelligence-embodied agents who can assess intentions and moods. 
The scales are constructed so that the measurements can be used broadly for comparisons of the social presence across different media, tasks and interactive settings.

The operationalization of the literature and theory previously formulated can be achieved at several levels. Specifically, Level 1: Co-presence is a necessary but not sufficient requirement for the sense of social presence. Level 2: the Subjective level, challenges to measure the psycho-behavioral accessibility of another actor. Finally, Level 3: the Intersubjective level, measures within and cross-actor symmetry. The purpose of the application of these levels in this research is to compare various mediated interactions, as well as for further theoretical inquiry.

Three social presence orders are considered in Formula 10 with reference to:

Co-presence (Co): to measure the degree to which individuals feel as if they are together in the same space.

Psycho-behavioral interaction (Pi): to measure individuals' perception of attention, emotional contagion, and mutual understanding with their colleagues. Perceived psychological engagement and perceived behavioral interdependence are independently analyzed.

Intersubjective symmetry (Is): to measure the degree to which the individual perceives that others share the same state of social presence.

$$
o B=\sum_{n=1}^{2} C o+\sum_{n=1}^{3} P i+\sum_{n=1}^{3} I s
$$

\section{Collective intelligence affinity}

Collective Intelligence Affinity is extracted by understanding mass user-generated content (knowledge), with an emphasis on integration and bridging. Individuals are producers, enablers and linkers of such content. Their preferences, abilities and capabilities are directly related to it and are represented by means of their behaviors in virtual settings.

The combination of the results obtained from the measurements are performed, considering a linear approach for the Personal, Community and Online behaviors as shown in the following formula:

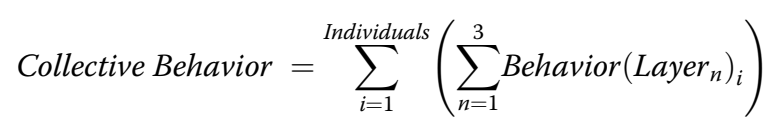

The results of the cognitive preferences, which are the result of Sternberg's Thinking Style Inventory (TSI) and Felder and Silverman's Learning Style Model (FSLSM), are considered independently, using their respective scales as shown in Formula 7.

Collective Intelligence understood as a social system is supported basically in human experience and can transform group unconsciousness into collective consciousness. That transformation does not need the cocreation of a new emerging online capacity, but alignment of the environmental resources and individuals. This affinity needs to be fundamentally analyzed within the function of cognitive and collective behaviors, as represented by the following formula:

$$
\text { Affinity }(C I)=f(\text { Collective Behavior, Cognitive Behavior })
$$

The management of knowledge from Collective Intelligence represents a vast difference from traditional methods of information allocation, since managing Collective Intelligence poses new requirements. For instance, semantic analysis has to merge information coming both from the content itself and the social/individual context. In addition, the social dynamics that emerge online have to be taken into account.

\section{Methods}

\section{Conducting measurements}

The measurements are to be carried out during three months with a network of about 2500 teleworkers working for 15 companies, geographically dispersed across Germany and Austria. The profiles of those teleworkers are mainly specialists in business segments such as travel, automobile, financial services, teleshopping, healthcare and energy, who provide telephonic assistance to nearly 800000 inquiries per month. All of them are already using an installed software application on their PCs, called Talent Media Interface (TMI), that allows them to work remotely, with consideration of all the security and data protection mechanisms required by the German authorities.

The TMI has embedded learning and assessment tools, which allow the dynamic integration of electronic surveys. The triggering of surveys can be configured in such a way that they do not disturb the normal work of the teleworkers. Each survey can be triggered: exactly after logging into the system, after a defined idle time, or at the end of a shift. Teleworkers work in daily shifts, rotating during the mornings, afternoons or evenings. The surveys automatically start, depending on their configuration. Teleworkers are prompted by a pop-up window in the middle of their screens to participate in it. If they do not want to, they are asked again in the next session when they log into the system. Reminders are triggered automatically only if the teleworker has not completely answered the survey within the defined period of time. This increases the chances that most of the surveys will be completed.

In order to make the measurements as easy and quick as possible for teleworkers, the surveys are designed by using check boxes and drop downs. They are divided into small web pages to avoid the need for scrolling. 
Table 7 Consolidated scoring methodology

\begin{tabular}{|c|c|c|c|c|}
\hline Layer & Primary Purpose & Aspects of Focus & Main Methods & Secondary Benefits \\
\hline \multicolumn{5}{|l|}{ Cognitive Behavior } \\
\hline Self-government Pattern & $\begin{array}{l}\text { Identify the level of affinity to work } \\
\text { remotely and in virtual teamwork }\end{array}$ & $\begin{array}{l}\text { Reflect different ways in which people } \\
\text { can organize or govern themselves }\end{array}$ & $\begin{array}{l}\text { Sternberg's Thinking Style } \\
\text { Inventory (TSI) }\end{array}$ & $\begin{array}{l}\text { Identify group behaviors considering } \\
\text { Theory of Group Dynamics }\end{array}$ \\
\hline Learning Pattern & $\begin{array}{l}\text { Identify individual's learning } \\
\text { preferences to determine the ideal } \\
\text { environment in which knowledge } \\
\text { can be processed better }\end{array}$ & $\begin{array}{l}\text { Identify tendencies to learn and process } \\
\text { knowledge with specific empathy and } \\
\text { effectiveness for hypermedia tools }\end{array}$ & $\begin{array}{l}\text { Felder and Silverman's Learning } \\
\text { Style Model (FSLSM) }\end{array}$ & $\begin{array}{l}\text { In-depth investigation of learning style } \\
\text { characteristics could also improve } \\
\text { pedagogical models, supporting more } \\
\text { effective and personalized online learning }\end{array}$ \\
\hline Personal Behavior & $\begin{array}{l}\text { Identify self-efficacy. Motivation and } \\
\text { performance are determined by how } \\
\text { successful people believe they can be }\end{array}$ & $\begin{array}{l}\text { Develop and improve self-efficacy } \\
\text { beliefs in teams by focusing on four } \\
\text { primary sources }\end{array}$ & General Self-Efficacy Scale (GSE) & $\begin{array}{l}\text { Recognize the importance of the } \\
\text { environment in determining behavior }\end{array}$ \\
\hline \multirow[t]{3}{*}{ Community Behavior } & \multirow[t]{3}{*}{$\begin{array}{l}\text { Identify a sense of 'belonging' and the } \\
\text { concrete experience of social networks }\end{array}$} & \multirow[t]{3}{*}{$\begin{array}{l}\text { Refer to accessed social resources } \\
\text { instead of occupational prestige }\end{array}$} & \multirow[t]{3}{*}{ The Resource Generator } & $\begin{array}{l}\text { Evaluate the desire for making/discovering } \\
\text { new contacts }\end{array}$ \\
\hline & & & & Integration of different types of relationships \\
\hline & & & & $\begin{array}{l}\text { Expectation and propensity to mobilize } \\
\text { social resources }\end{array}$ \\
\hline Online Behavior & $\begin{array}{l}\text { Assess interaction with others with } \\
\text { regard to mediatic interfaces }\end{array}$ & $\begin{array}{l}\text { Assess various levels of social presence } \\
\text { from simple co-presence to more intense } \\
\text { feelings of psychological and behavioral } \\
\text { accessibility and interaction }\end{array}$ & $\begin{array}{l}\text { Networked Minds Social Presence } \\
\text { Inventory }\end{array}$ & $\begin{array}{l}\text { Assess intentions and moods when using } \\
\text { collaborative virtual environments and } \\
\text { artificial intelligence }\end{array}$ \\
\hline
\end{tabular}


Each survey should not take more than 5 min to answer. An overview of the behavior layers and scoring methodologies is presented in Table 7. The assessments will be done in four different sessions, each one of two weeks. There will be a break period of one week in between to avoid any overload.

Since we use electronic surveys, all information will be collected in a central database, where unique IDs will be stored for each of the answers. Unique teleworker IDs are also considered in order to link the four sessions and to present a general report on each individual.

\section{Conclusions}

In this study, novel techniques for exploiting multiple layers of interaction in user behavior have been presented. These layers constitute the basis for identifying factors to facilitate interaction and creation of content through Collective Intelligence. Collective Intelligence provides added value to the available information, transforming it into knowledge and enabling the accomplishment of tasks that are not otherwise possible in existing procedures and workflows.

The transformation of information into knowledge happens only when exchange of information takes place and when the result of the discussion or its analysis can be used for any meaningful purpose. Irrespective of how we codify and store any generated knowledge, it does not have much meaning until it is used or shared for some purpose. We believe that the individual identification, measurement and alignment of cognitive, social and personal behaviors in online environments allow information to be more effectively transformed into knowledge through synchronized collaboration involving empathy at all possible levels.

We presented a set of patterns modeling an approach for identifying affinity of cognitive styles to perform remote work and virtual teamwork, as well hypermedia preferences based on learning styles. Differing from previous research studies in this field, this study combines two different rule-based mechanisms, namely Thinking Style Inventory (TSI) and Index of Learning Styles (ILS) to calculate scores and identify individuals' affinities and preferences that can be used as a basis for identifying environmental settings and selecting hypermedia tools where individuals perform better and also process knowledge in an effective way. The approach is not proposed for one specific type of organization, but rather for any individual working in virtual settings in general.

Future work deals with verification of our approach to further investigate knowledge transfer in virtual settings. For this, we intend to map out additional teamwork experiments in virtual settings and compare them with the results obtained from questionnaires used for the respective cognitive learning styles' analysis and social theory behaviors.
By focusing on the recognition of supplementary environmental and social conditions, cognitive preferences and behavior of individuals in online communities, we believe new virtual settings can be defined as alternative methods in which collectivities can organize themselves and improve knowledge sharing. In addition to that, by making individuals' cognitive styles and environments compatible through the effective implementation of hypermedia and telecommunication technologies, individuals will be better equipped to receive and interpret relevant information and use it to decide how to act and perform effectively in virtual settings.

To rapidly and effectively create knowledge, online collaboration should not occur in a standard manner using all the same tools and resources in the same way; it should be personalized according to the preferences and abilities of the individuals involved. The well-used diversity of participants in a community assists in overcoming blind spots and ignorance. They can see a bigger, and more complete picture and develop better outcomes that they can accomplish alone. The spectrum of this effective collaboration is what we identify as Collective Intelligence. It is fundamental that the online environment and tools are 'cognitively calibrated' with the individuals to enhance the process of information exchange, making it a key component of creating richer knowledge communities.

\section{Competing interests}

The author(s) declare that they have no competing interests.

\section{Authors' contributions}

SC carried out the cognitive studies, evaluated the integration of social theories and participated in evaluating different virtual setting scenarios with teleworkers in Germany. The sequence alignment and drafted the manuscript was done between SC and CM who lead the design of the study. Both authors approved the final manuscript.

Received: 1 December 2014 Accepted: 16 June 2015

Published online: 03 September 2015

\section{References}

1. Allport, FH, \& Lepkin, M. (1943). Building war morale with news headlines. Public Opinion Quarterly, 7, 211-221.

2. DeSanctis, G, \& Monge, P. (1999). Introduction to the special issue: communication processes for virtual organizations. Organization Science, 10, 693-703.

3. Stewart, GL, \& Barrick, MR. (2000). Team structure and performance: Assessing the mediating role of intrateam process and the moderating role of task type. Academy of Management Journal, 43, 135-148.

4. Mark, G. (2001). Meeting current challenges for virtually collocated teams: participation, culture, and integration. In L Chidambaram \& I Zigurs (Eds.), Our Virtual World: The Transformation of Work, Play and Life Via Technology (pp. 74-93). Hershey USA: Idea group publishing.

5. Jarvenpaa, SL, \& Leidner, DE. (1999). Communication and trust in global virtual teams. Organization Science, 10(6), 791-815.

6. Paul, DL, \& McDaniel, RR, Jr. (2004). A field study of the effect of interpersonal trust on virtual collaborative relationship performance. MIS Quarterly, 28(2), 183.

7. Payne, HJ. (2005). Reconceptualizing social skills in organizations: exploring the relationship between communication competence, job performance, and supervisory roles. Journal of Leadership \& Organizational Studies, 11(2), 63.

8. Gist, ME, \& Mitchell, TR. (1992). Self-efficacy: A theoretical analysis of its determinants and malleability. Academy of Management Review, 17(2), 183-211. 
9. Malhotra, A, \& Majchrzak, A. (2004). Enabling knowledge creation in far-flung teams: best practices for IT support and knowledge sharing. Journal of Knowledge Management, 8, 75-88.

10. Townsend, AM, DeMarie, SM, \& Hendrickson, AR. (1998). Virtual teams: technology and the workplace of the future. Academy of Management Executive, 12, 17-29.

11. Fussell, SR, \& Benimoff, I. (1995). Social and cognitive processes in interpersonal communication: Implications for advanced telecommunications technologies. Human Factors, 37, 228-250.

12. Daft, RL, \& Lengel, RH. (1986). Organizational informa- tion requirements, media richness and structural design. Man-agement Science, 32, 554-571.

13. Ko, D-G, Kirsch, LJ, \& King, WR. (2005). Antecedents of knowledge transfer from consultants to clients in enterprise system implementations. MIS Quarterly, 29, 59-85.

14. Wilson, T. (2002). The Nonsense of "Knowledge Management" Information Research, vol 5. paper no. 144

15. De Bono, E. (2000). Thinking Course. Great Britain: BBC Book.

16. Harrison, AF, \& Bramson, RM. (1984). The Art of Thinking. New York: The Berkley Publishing Group.

17. Kwok, JSH, \& Gao, S. (2004). "Knowledge-sharing community in P2P network: a study of motivational perspective". Journal of Knowledge Management, 8(1), 94-102.

18. Soule, DL. (2003). Bridging Knowledge Gaps: Knowledge Sharing and Learning Practices in Virtual Development Teams", DBA Thesis. Cambridge, MA: Harvard University.

19. Zakaria, N, Amelinckx, A, \& Wilemon, D. (2004). Working Together Apart? Building A Knowledge-Sharing Culture for Global Virtual Teams, Creativity and Innovation Management, Vol. 13 No. 1 (pp. 15-29). Sternberg, R. J. (1988). Mental self-government: A theory of intellectual styles and their development. Human Development, 31, 197-224.

20. Ghani, N, Tahsildari, H, Keshvarsima, A, Masrom, M, \& Hashim, M. (2008). The Influence of Employees Thinking Styles in Knowledge Sharing Through Collaborative Virtual Environments.

21. Sternberg, RJ. (1988). Mental self-government: a theory of intellectual styles and their development. Human Development, 31, 197-224.

22. Sternberg, RJ. (1997). Thinking Styles. NY: Cambridge University Press.

23. Hayes, J, \& Allinson, CW. (1998). Cognitive style and the theory and practice of individual and collective learning in organizations. Human Relations, $51,847-871$

24. Carver, CA, Howard, RA, \& Lane, WD. (1999). Addressing different learning styles through course hypermedia. IEEE Transactions on Education, 42(1), 33-38.

25. Dunn, K, \& Dunn, R. (1987). "Dispelling Outmoded Beliefs About Student Learning" Educational Leadership.

26. Workman, M, Kahnweiler, W, \& Bommer, WH. (2003). The effects of cognitive style and technology media on commitment to telework and virtual teams. Journal of Vocational Behavior, 63, 199-21.

27. Stout, RJ, Cannon-Bowers, JA, Salas, E, \& Milanovich, DM. (1999). Planning, shared mental models, and coordi-nated performance: An empirical link is established. Human Factors, 41, 61-71.

28. Volkma, RJ, \& Gorman, RH. (1998). The influence of cognitive-based group composition on decisionmaking process and outcome. Journal of Management Studies, 35, 105-121.

29. Heald, MR, Contractor, NS, Koehly, LM, \& Wasserman, S. (1998). Formal and emergent predictors of coworkers perceptual congruence on an organizations social structure. Human Communication Research, 24, 536-563.

30. Jehng, JJ. (1997). The psycho-social processes and cognitive effects of peer-based collaborative interactions with com-puters. Journal of Educational Computing Research, 17, 19-46.

31. Baruch, Y, \& Nicholson, N. (1997). Home, sweet work: requirements for effective home working. Journal of General Management, 23, 15-31.

32. Hill, EJ, Miller, BC, Weiner, SP, \& Colihan, J. (1998). Influences of the virtual office on aspects of work and work/life balance. Personnel Psychology, 51, 667-683.

33. Wieland, R. (1999). Mental workload in VDU-assisted office work: consequences for the design of telework. Zeitschrift Fur Arbeits-Und Organisationaspsychologie, 43, 153-158.

34. Ferrari, M, \& Sternberg, RJ. (1998). The Development of Mental Abilities and Styles. In W Damon, D Kuhn, \& RS Siegler (Eds.), Handbook of Child Psychology: Vol. 2 (5th ed., pp. 899-946). NY: Wiley.

35. Civin, MA. (1999). On the vicissitudes of cyberspace as potential space. Human Relations, 52, 485-506.
36. Fusaro, B. (1997). How do we set up a telecommuting program that really works? PC World, 15, 238-247.

37. Wellman, B, Salaff, J, Dimitrova, D, Garton, L, Gulia, M, \& Haythornthwaite, C. (1996). Computer networks as social networks: collaborative work, telework and virtual community. Annual Review of Sociology, 22, 213-238.

38. Duxbury, L. (1999). An empirical evaluation of the impact of telecommuting on intra-organizational communication. Journal of Engineering and Technology Management, 16, 1-28.

39. Cerulo, KA. (1997). Reframing sociological concepts for a brave new (virtual?) world. Sociological Inquiry, 67, 48-58.

40. Ngwenyama, OK, \& Lee, AS. (1997). Communication Richness in Electronic Mail: Critical Social Theory and the Contextuality of Meaning. MIS Quarterly (pp. 145-166).

41. Workman, M. (2001). Collectivism, individualism, and cohesion in a team-based occupation. Journal of Vocational Behavior, 58, 82-97.

42. Atkinson, S. (1998). Cognitive style in the context of design and technology project work. Educational Psychology, 18, 183-194.

43. Lim, KH, \& Benbasat, I. (2000). The effect of multimedia on perceived equivocality and perceived usefulness of information systems. MIS Quarterly, $24,449-471$

44. Lewin, K. (1951) Field Theory in Social Science; Selected Theoretical Papers. D. Cartwright (ed.). New York: Harper \& Row.

45. Fritz, MBW, Narasimhan, S, \& Rhee, HS. (1996). The Impact of Remote Work on Informal Organizational Communication. Telecommuting ?96 Proceedings, April, Jacksonville, FL (pp. 1-20).

46. Heald, MR, Contractor, NS, Koehly, LM, \& Wasserman, S. (1998). Formal and emergent predictors of coworkers? perceptual congruence on an organization?s social structure. Human Communication Research, 24, 536-563.

47. Chmiel, A, Sienkiewicz, J, Thelwall, M, Paltoglou, G, Buckley, K, Kappas, A, \& Holyst, JA. (2011). Collective emotions online and their influence on community life. PLoS One, 6(7), e22207.

48. McGrath, Joseph Edward. (1984). Groups: Interaction and Performance. Englewood Cliffs, N.J.: Prentice-Hall.

49. Kraiger, K, Ford, JK, \& Salas, E. (1993). Application of cognitive, skill-based and affective theories of learning outcomes to new methods of training evaluation. Journal of Applied Psychology, 78(2), 311.

50. Kock, N. (2004). The psychobiological model: towards a new theory of computer-mediated communication based on Darwinian evolution. Organization Science, 15, 327-348.

51. Bandura, A. (1986). Social Foundations for Thought and Action: A Social Cognitive Theory. Englewood Cliffs, NJ: Prentice-Hall.

52. Field, J. (2003). Social Capital. London: Routledge.

53. Bourdieu, P. (1983). Forms of capital'. In JC Richards (Ed.), Handbook of Theory and Research for the Sociology of Education. New York: Greenwood Press.

54. Kehrwald, B. (2008). Understanding social presence in text-based online learning environments. Distance Education, 29(1), 89-106.

55. Wei, C, Chen, N, \& Kinshuk. (2012). A model for social presence in online classrooms. Educational Technology Research And Development, 60(3), 529-545.

56. Norton, RW. (1986). Communicator style in teaching: Giving good form to content. In JM Civikly (Ed.), Communicating in college classrooms (pp. 33-40). San Francisco: Jossey-Bass.

57. teVan der Gaag, MPJ, \& Snijders, TAB. (2005). The Resource Generator: measurement of individual social capital with concrete items. Social Networks, 27, 1-29. Introduces a new measurement instrument, and a new methodology to specify measures.

58. Woolley, AW, Chabris, CF, Pentland, A, Hashmi, N, \& Malone, TW. (2010). Evidence for a collective intelligence factor in the performance of human groups. Science, 330(2010), 686-688.

59. Felder \& Soloman, (1991, 1994). Index of Learning Styles (ILS). [viewed 12 Nov 2013, verified 12 Nov 2013] http://www4.ncsu.edu/unity/lockers/users/ f/felder/public/ILSdir/ILS.pdf

60. Flap, HD. (1999). Creation and returns of social capital: a new research program. La Revue Tocqueville, 20, 5-26.

61. Snijders, TAB. (1999). Prologue to the measurement of social capital. La Revue Tocqueville, 20, 27-44.

62. Lin, N, \& Dumin, M. (1986). Access to occupations through social ties. Social Networks, 8, 365-85.

63. Lin, N. (2001). Social Capital: a Theory of Social Structure and Action Cambridge: Cambridge University Press.

64. Argote, L. (1999). Organizational Learning: Creating, Retailing and Transferring Knowledge. Norwell, MA, USA: Kluwer Aca- demic Publishers. 
65. Fischer, J, Gündling, N, Harcks, A, \& Schnöger, C. (2012). Work@Home, Ein Kommunikationsprojekt, Gesellschafts- und Wirschaftskommunikation. Berlin: Universität der Künste.

66. Frank, PH.D, M. (2011). The pillars of the self concept: Self-esteem and self-efficacy. Retrieved from http:/www.excelatlife.com/articles/ selfesteem.htm

Submit your manuscript to a SpringerOpen ${ }^{\odot}$ journal and benefit from:

- Convenient online submission

- Rigorous peer review

- Immediate publication on acceptance

- Open access: articles freely available online

- High visibility within the field

- Retaining the copyright to your article

Submit your next manuscript at $\boldsymbol{\nabla}$ springeropen.com 